\title{
Multivariate Analysis of the Survival Rate for Treatment Modalities in Incurable Stage IV Colorectal Cancer
}

\author{
Sung Kang Kim, Chang Ho Lee, Min Ro Lee, Jong Hun Kim \\ Department of Surgery, Chonbuk National University Medical School, Jeonju, Korea
}

Purpose: The aim of this study was to compare survival in patients that underwent palliative resection treatment versus nonresection for incurable colorectal cancer (ICRC).

Methods: The case records of 201 patients with ICRC between January 2000 and December 2009 were reviewed. Demographics, American Society of Anesthesiologists (ASA) score, carcinoembryonic antigen (CEA) level, the location of the colon cancer, histology, metastasis, treatment options and median survival were analyzed retrospectively. We divided the patients into four groups according to the treatment modalities: resection alone, resection with post-operative chemotherapy, non-resection treatment by chemotherapy alone, and stent or bypass. Median survival times were compared according to each treatment option, and the survival rates were analyzed.

Results: 105 patients underwent palliative resection whereas 96 were treated with non-resection modalities. A palliative resection was performed in 44 cases for resection alone and in 61 cases for resection with post-operative chemotherapy. In patients treated with non-resection of the primary tumor, chemotherapy alone was done in 65 cases and stent or bypass in 31 cases. Multivariate analysis showed a median survival of 14 months in patients with palliative resections with post-operative chemotherapy, which was significantly higher than those for chemotherapy alone (8 months), primary tumor resection alone (5 months), and stent or bypass (5 months). Gender, age, ASA score, CEA level, the location of colon cancer, histology and the presence of multiple metastases were not independent factors in association with the median survival rate.

Conclusion: In the treatment of ICRC, palliative resection followed by post-operative chemotherapy shows the most favorable median survival compared to other treatment options.

Keywords: Colorectal cancer; Palliative; Stents; Bypass

\section{INTRODUCTION}

According to recent cancer statistics released by the Korean government, the incidence rate of colorectal cancer takes 3rd place, following stomach and thyroid cancer, and in terms of death rate, colorectal cancer takes 4th place, following lung cancer, liver cancer and stomach cancer [1]. A radical resection is understood to

Received: June 16, 2011 Revised: August 3, 2011

Accepted: September 15, 2011

Correspondence to: Min Ro Lee, M.D.

Department of Surgery, Chonbuk National University Medical School,

567 Baekje-daero, Deokjin-gu, Jeonju 561-756, Korea

Tel: +82-63-250-1570, Fax: +82-63-271-6197

E-mail:gsminro@chonbuk.ac.kr

(C) 2012 The Korean Society of Coloproctology

This is an open-access article distributed under the terms of the Creative Commons Attribution NonCommercial License (http://creativecommons.org/licenses/by-nc/3.0) which permits unrestricted noncommercial use, distribution, and reproduction in any medium, provided the original work is properly cited. be the most effective treatment for colorectal cancer [2]. However, in about $20 \%$ of the cases, the colorectal cancer is found to be progressive, and complete removal of the lesion at the time of diagnosis is impossible; accordingly, various palliative treatments are required $[3,4]$. Since the majority of these patients are old and have bad condition overall with various underlying diseases, it is still debatable whether surgical removal of the primary lesion will enhance survival rate or not [3,5-10].

As non-operative methods, chemotherapy, stent insertion, and bypass are used. A number of studies have reported that in the case of chemotherapy, the median survival period and the overall survival rate can be increased by using a single treatment modality without removing the primary lesion [11-13]. In addition, stent insertion and bypass, which is expected to develop fewer complications, are restrictively chosen to relieve the symptoms of the primary obstructive lesion [3]. Further, efforts have been made to find the best treatment modality for advanced colorectal cancer and to 
confirm whether a palliative resection contributes to enhancing the survival rate of colorectal cancer patients. For these reasons, the authors wanted to find the optimal treatment modality by comparing survival rates attained by using various treatment modalities for colorectal cancer.

\section{METHODS}

A group of colorectal cancer patients who were pathohistologically given a definite diagnosis of colorectal cancer and who had received treatments but had been confirmed as being unable to undergo a radical resection due to multiple or single metastasis findings at Chonbuk National University Hospital between January 2000 and December 2009 were selected. Advanced colorectal cancer is defined as cases with multiple lesions of the liver or with lung metastasis, which could not be resected according to preoperative findings, such as chest X-ray, chest computed tomography, magnetic resonance imaging, and positron emission tomography, or according to operative findings; cases with multiple metastasis findings; and cases with local invasions that could not be R0 resected due to disseminated peritoneal metastases, synchronous multiple metastasis to organs in the abdominal cavity, and lymphatic metastases whose lesion could not be resected. The present study was carried out over 10 years and involved 207 individuals diagnosed with advanced colorectal cancer. Of the 207 patients, 201 individuals were finally selected. Three cases that could not be monitored and another three cases of neuroendocrinal tumors were excluded from this retrospective study.

Subjects were divided by sex, age and level of anesthetic risk provided by American Society of Anesthesiologists (ASA), and correlations between survival rate and location of primary lesion, pretreatment carcinoembryonic antigen (CEA), tumor differentiation, symptoms and metastasis were examined. In order to find survival rates by treatment modality, subjects were divided into groups of palliative resection, palliative resection followed by chemotherapy, stent insertion and bypass for comparison. Post-operative complications were defined as respiratory or wound infection, anastomotic leakage, bleeding, intraperitoneal abscess, ileus, voiding difficulty, anastomosis site obstruction, and conditions requiring additional surgical or medical treatments. Post-operative death was defined as surgery-related death occurring within 30 days of surgery.

The SPSS ver. 17.0 (SPSS Inc., Chicago, IL, USA) was used for statistical treatment. For the survival rate analysis, the Kaplan-Meier method was used. After the log rank test, statistical significance was established with a P-value less than 0.05 . When sufficiently meaningful data were obtained through a univariate analysis, a multivariate analysis was conducted using the Cox proportional hazards regression model.

\section{RESULTS}

\section{Properties of the resection and the non-resection groups}

Out of the total 201 patients, 105 individuals (52\%) underwent a palliative resection, and $96(48 \%)$ were in the non-resection group (Fig. 1). The male-to-female ratios in the palliative resection and the non-resection groups were 2.18:1 (72:33) and 1.82:1 (62:34), respectively. The numbers of patients 75 years or older were 14 (13.3\%) and $21(21.9 \%)$ in the respective palliative resection and the non-resection groups. The numbers of patients having $5 \mathrm{ng} / \mathrm{mL}$ or more of CEA (normal range, 0.0 to $5.0 \mathrm{ng} / \mathrm{mL}$ ) prior to treatment were $72(73.5 \%)$ and $78(83.0 \%)$ in the respective groups. The numbers of patients having primary lesions of colon cancer were $60(57.1 \%)$ and $54(56.2 \%)$ in the respective palliative resection and non-resection groups. In addition, the numbers of patients

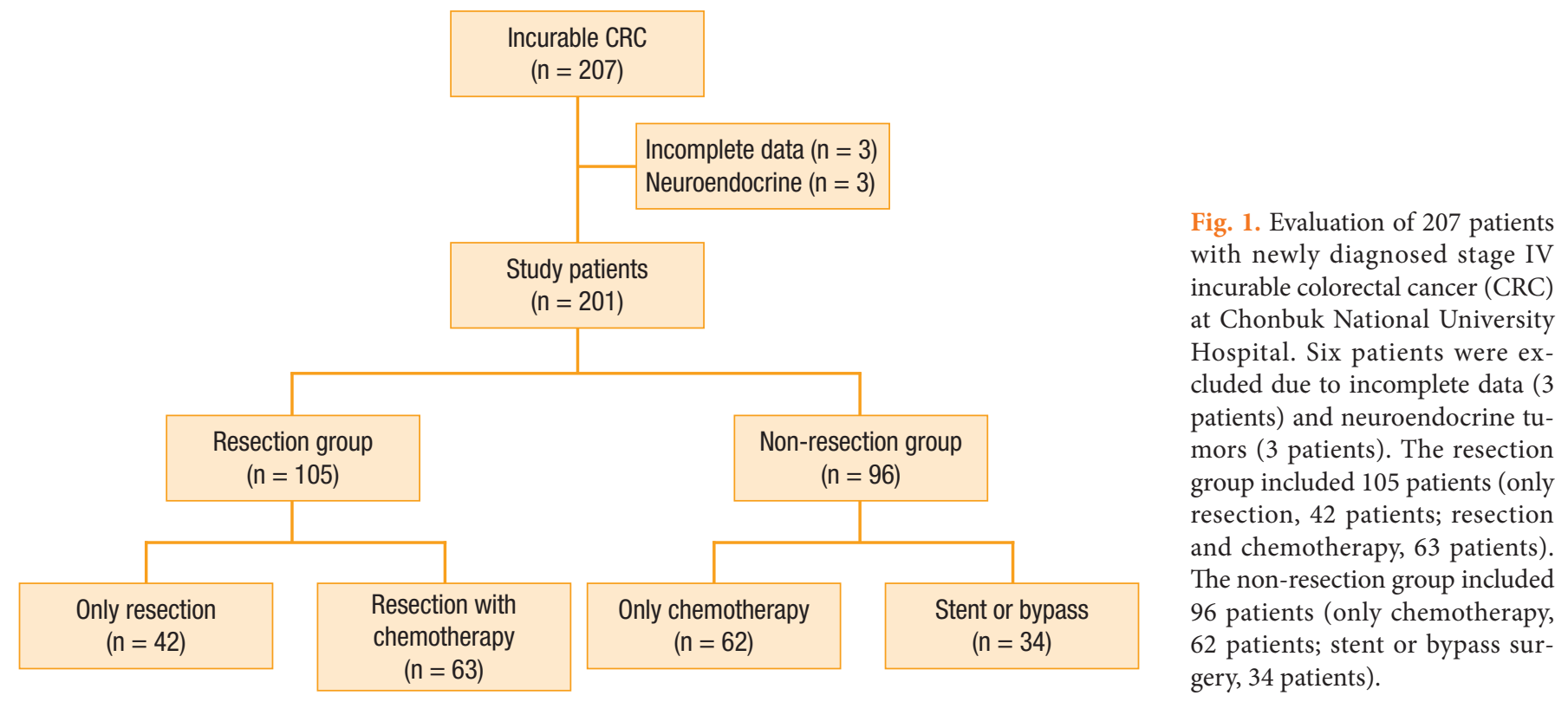


who had good ASA values (1 to 2) were 96 (91.4\%) in the resection group and $77(80.2 \%)$ in the non-resection group, meaning a better ASA score in the resection group $(\mathrm{P}=0.02)$ (Table 1$)$.

Major complaints of the resection group at the first visit included abdominal pain (46.4\%), bowel habit change (21.4\%), and bleeding $(5.1 \%)$; those of the non-resection group included abdominal pain $(31.2 \%)$, nonspecific symptoms (29.3\%), and bowel habit change $(16.4 \%)$. Ileus was confirmed with radiological findings with symptoms of abdominal distention and nausea. Surgery was conducted when the primary lesion could be surgically resected according to the characteristics of the tumor and the judgment of the surgeon (Table 2).

\section{Properties of primary cancer}

The numbers of primary cancer cases by location of the lesion in the respective resection and non-resection groups were 37 (35.2\%) and $43(44.8 \%)$ in rectum, followed by $28(26.7 \%)$ right colon cases in the resection group, and 15 (15.6\%) sigmoid colon cases in the

Table 1. Baseline characteristics of study patients

\begin{tabular}{lcccc}
\hline Characteristic & $\begin{array}{c}\text { All } \\
(\mathrm{n}=201)\end{array}$ & $\begin{array}{c}\text { Resection } \\
(\mathrm{n}=105)\end{array}$ & $\begin{array}{c}\text { Non- } \\
\text { resection } \\
(\mathrm{n}=96)\end{array}$ & P-value \\
\hline Male sex & $134(66.7)$ & $72(68.6)$ & $62(64.6)$ & 0.55 \\
Old age ( $\geq 75 \mathrm{yr})$ & $35(17.4)$ & $14(13.3)$ & $21(21.9)$ & 0.11 \\
Good ASA score (1-2) & $173(86.1)$ & $96(91.4)$ & $77(80.2)$ & 0.02 \\
$\begin{array}{l}\text { CEA elevation } \\
\quad(n=192)\end{array}$ & $150 / 192$ & $72 / 98$ & $78 / 94$ & 0.11 \\
Primary colon cancer & $(78.1)$ & $(73.5)$ & $(83.0)$ & \\
Multiple metastases $^{\mathrm{a}}$ & $114(56.7)$ & $60(57.1)$ & $54(56.2)$ & 0.90 \\
\hline
\end{tabular}

Values are presented as number (\%).

ASA, American Society of Anesthesiologists; CEA, carcinoembryonic antigen.

${ }^{a}$ According to classification of American Joint Committee on Cancer, 7th edition.

Table 2. Main presenting symptoms of patients with incurable colorectal cancer

\begin{tabular}{lcccc}
\hline \multirow{2}{*}{ Symptom } & Resection & \multicolumn{2}{c}{ Non-resection group } & \\
\cline { 3 - 4 } & group & $\begin{array}{l}\text { Chemo- } \\
\text { therapy }\end{array}$ & $\begin{array}{c}\text { Stent or } \\
\text { bypass }\end{array}$ & Total \\
\hline Pain & $52(46.4)$ & $20(29.4)$ & $15(31.2)$ & $35(30.2)$ \\
Obstruction & $12(10.7)$ & $2(2.9)$ & $8(16.6)$ & $10(8.6)$ \\
Bleeding & $17(15.1)$ & $3(4.4)$ & $5(10.4)$ & $11(9.5)$ \\
Bowel habit change & $24(21.4)$ & $10(14.7)$ & $9(18.7)$ & $19(16.4)$ \\
Screening & $4(3.6)$ & $33(48.5)$ & $1(2.0)$ & $34(29.3)$ \\
Palpable mass & $3(2.7)$ & $0(0)$ & $0(0)$ & $0(0)$ \\
Total & $112^{\mathrm{a}}$ & 68 & 48 & $116^{\mathrm{b}}$ \\
\hline
\end{tabular}

Values are presented as number (\%).

${ }^{\text {aThere were }} 112$ symptoms in 105 patients of the resection group; ${ }^{\mathrm{b}}$ There were 116 symptoms in 96 patients of the non-resection group. non-resection group (Table 3). According to the results of endoscopic biopsies for the non-resection group and tumor differentiation of the surgically-removed lesion, the number of well-differentiated adenocarcinoma cases was $16(84.2 \%)$ in the non-resection group compared with only 3 cases $(15.8 \%)$ in the resection group (Table 4).

\section{Metastasized lesion}

The number of hepatic metastasis cases were 50 (47.6\%) and 32 $(33.3 \%)$ in the respective resection and non-resection groups, followed by $28(26.7 \%)$ and $24(25.0 \%)$ of peritoneal metastasis in the

Table 3. Sites of the primary tumor

\begin{tabular}{lccc}
\hline Site & $\begin{array}{c}\text { Resection } \\
(\mathrm{n}=105)\end{array}$ & $\begin{array}{c}\text { Non-resection } \\
(\mathrm{n}=96)\end{array}$ & $\begin{array}{c}\text { Total } \\
(\mathrm{n}=201)\end{array}$ \\
\hline Right colon & $28(26.7)$ & $14(14.6)$ & $42(20.9)$ \\
Transverse colon & $8(7.6)$ & $9(9.4)$ & $17(8.5)$ \\
Descending colon & $4(3.8)$ & $8(8.3)$ & $12(6.0)$ \\
Sigmoid colon & $19(18.1)$ & $15(15.6)$ & $34(16.9)$ \\
Recto-sigmoid colon & $9(8.6)$ & $7(7.3)$ & $16(8.0)$ \\
Rectal & $37(35.2)$ & $43(44.8)$ & $80(38.9)$ \\
\hline
\end{tabular}

Values are presented as number (\%).

Table 4. Comparison of the frequency of treatment methods according to tumor differentiation (test for trend)

\begin{tabular}{lrcc}
\hline Tumor differentiation & $\begin{array}{c}\text { Resection }^{\mathrm{a}} \\
(\mathrm{n}=105)\end{array}$ & $\begin{array}{c}\text { Non-resection } \\
(\mathrm{n}=96)\end{array}$ & P-value \\
\hline Well $(\mathrm{n}=19)$ & $3(15.8)$ & $16(84.2)$ & 0.01 \\
Moderate $(\mathrm{n}=140)$ & $80(57.1)$ & $60(42.9)$ & \\
Poor $(\mathrm{n}=29)$ & $10(34.5)$ & $19(65.5)$ & \\
Mucinous $(\mathrm{n}=13)$ & $12(92.3)$ & $1(7.7)$ & \\
\hline
\end{tabular}

Values are presented as number (\%).

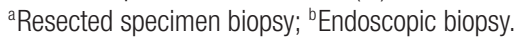

Table 5. Sites of metastasis in incurable colorectal cancer

\begin{tabular}{lccc}
\hline Site & $\begin{array}{c}\text { Resection } \\
(\mathrm{n}=105)\end{array}$ & $\begin{array}{c}\text { Non-resection } \\
(\mathrm{n}=96)\end{array}$ & P-value $^{\mathrm{a}}$ \\
\hline Liver & $50(47.6)$ & $32(33.3)$ & 0.174 \\
Lung & $10(9.5)$ & $8(8.3)$ & 0.681 \\
Liver and lung & $6(5.7)$ & $7(7.3)$ & 0.042 \\
Peritoneal seeding & $28(26.7)$ & $24(25.0)$ & 0.853 \\
Pelvic organ & $4(3.8)$ & $5(5.2)$ & 0.743 \\
Bone & $2(1.9)$ & $5(5.2)$ & 0.031 \\
Nominated lymph nodes & $3(2.8)$ & $3(3.1)$ & 0.931 \\
Combined & $2(1.9)$ & $12(12.5)$ & 0.014 \\
\hline
\end{tabular}

Values are presented as number (\%).

aFisher's exact test. 
respective groups. The numbers of multiple metastases and bone metastasis in the non-resection group were $12(12.5 \% ; \mathrm{P}=0.014)$ and $5(5.2 \% ; \mathrm{P}=0.031)$, respectively, and showed a statistically difference $(\mathrm{P}=0.014, \mathrm{P}=0.031)$ from the values of $2(1.9 \%)$ and 2 (1.9\%) for the resection group (Table 5).

\section{Treatment modality}

In the resection group, 35 (33.5\%) right hemicolectomies were conducted, followed by 26 (24.8\%) low anterior resections and 20 (19.0\%) anterior resections (Table 6). In the resection group, 63 patients $(60.0 \%)$ underwent post-operative chemotherapy, and in the non-resection group, 83 patients $(86.5 \%)$ did the same. The numbers of patients who underwent radiotherapy were $5(4.8 \%)$ and $24(25 \%)$ in respective resection and non-resection groups. Further, in the resection group, 42 patients (40\%) did not undergo chemotherapy: 19 cases of refusal of treatment, 8 cases of general weakness, 8 cases of being unable to monitor the patients, and 7 cases of post-operative complications (Table 7). Out of the total of $62 \mathrm{sub}$ jects in the chemotherapy group, 2 patients underwent an emergency colostomy during chemotherapy.

Four patients who were originally supposed to undergo a bypass switched to a resection: one right hemicolectomy and three low anterior resections. Out of the 20 bypass patients, 1 patient had to undergo surgery again due to an adhesive ileus. Additionally, out of the 14 stent insertion patients, 1 patient underwent a colostomy due to recurrent colonic obstruction, and another patient underwent surgery due to peritonitis caused by a perforation.

Table 6. Types of surgery

\begin{tabular}{lcc}
\hline Type & $\begin{array}{c}\text { Resection } \\
(\mathrm{n}=105)\end{array}$ & $\begin{array}{c}\text { Non-resection } \\
(\mathrm{n}=96)\end{array}$ \\
\hline Right hemicolectomy & $35(33.3)$ & $1(1.0)$ \\
Left hemicolectomy & $4(3.8)$ & \\
Anterior resection & $20(19.0)$ & \\
Low anterior resection & $26(24.8)$ & $3(3.1)$ \\
Hartmann's operation & $10(9.5)$ & \\
Miles' operation & $3(2.9)$ & \\
Subtotal colectomy & $6(5.7)$ & \\
Stoma formation or bypass & $18(17.1)$ & $20(20.8)$ \\
\hline
\end{tabular}

Values are presented as number (\%).

Table 7. Patients with other combination therapies

\begin{tabular}{lcc}
\hline Therapy & $\begin{array}{c}\text { Resection } \\
(\mathrm{n}=105)\end{array}$ & $\begin{array}{c}\text { Non-resection } \\
(\mathrm{n}=96)\end{array}$ \\
\hline Chemotherapy & $61(58.1)$ & $71(74.0)$ \\
Radiation therapy & $3(2.9)$ & $12(12.5)$ \\
Chemotherapy and radiation & $2(1.9)$ & $12(12.5)$ \\
\hline
\end{tabular}

Values are presented as number (\%).
Major post-operative complications and death rate

After resection, 17 (16.2\%) major complications, 5 cases $(4.7 \%)$ of anastomotic leakage, 4 cases $(3.8 \%)$ of bleeding, 3 cases $(2.9 \%)$ of lung complications, 3 cases (2.9\%) of ileus, 1 case (0.9\%) of heart disease, and 1 case $(0.9 \%)$ of acute renal failure, were reported. Three patients $(2.86 \%)$ died of pulmonary edema, sepsis and multiple organ failure after surgery.

\section{Analysis of the prognosis factors and the survival rate}

In both the resection and the non-resection groups of advanced colorectal cancer patients, factors such as sex, age, ASA score, location of the colorectal cancer lesion, existence of multiple metastases and tumor differentiation were not proven to be prognostic factors affecting survival rates. In terms of treatment modality, chemotherapy alone appeared to be a significant prognosis factor according to the univariate analysis, but was confirmed to be statistically insignificant through the multivariate analysis. Palliative resection followed by chemotherapy was confirmed to be a factor significantly affecting survival rates according to both the univariate and the multivariate analyses (relative risk [RR], 0.44; 95\% confidence interval [CI], 0.28 to 0.69 ; RR, 0.47 ; $95 \%$ CI, 0.28 to 0.79) (Table 8). In terms of survival rates, the group of palliative resection followed by chemotherapy showed a 14 months (range, 9.6 to 18.4 months) median survival rate while the chemotherapyalone treatment group and the group of either stent insertion or bypass showed 8 months (range, 5.6 to 10.4 months) and 5 months median survival rates, respectively (Fig. 2).

Table 8. Univariate and multivariate analyses of factors associated with survival in incurable colorectal cancer

\begin{tabular}{lcc}
\hline Factor & Univariate & Multivariate \\
\hline Female sex & $1.23(0.91-1.67)$ & $1.27(0.92-1.75)$ \\
Old age $(\geq 75 \mathrm{yr})$ & $1.90(1.28-2.82)$ & $1.49(0.98-2.28)$ \\
Good ASA score & $0.84(0.56-1.27)$ & $0.95(0.61-1.48)$ \\
Primary colon cancer & $1.32(0.98-1.77)$ & $1.22(0.89-1.66)$ \\
Multiple metastases & $1.24(0.93-1.66)$ & $1.33(0.98-1.81)$ \\
Tumor differentiation & & \\
Well & 1.00 & 1.00 \\
Moderate & $0.84(0.50-1.42)$ & $1.02(0.58-1.80)$ \\
Poor & $0.98(0.52-1.83)$ & $1.23(0.62-2.41)$ \\
$\quad$ Mucinous & $0.59(0.28-1.28)$ & $0.80(0.35-1.85)$ \\
Treatment modality & 1.00 & 1.00 \\
Stent or bypass & $0.62(0.40-0.97)$ & $0.64(0.39-1.05)$ \\
Only chemotherapy & $0.97(0.60-1.55)$ & $0.93(0.55-1.57)$ \\
Only resection & $0.44(0.28-0.69)$ & $0.47(0.28-0.79)$ \\
\hline Resection + chemotherapy & & \\
\hline
\end{tabular}

Values are presented as relative risk (95\% confidence interval). ASA, American Society of Anesthesiologists. 


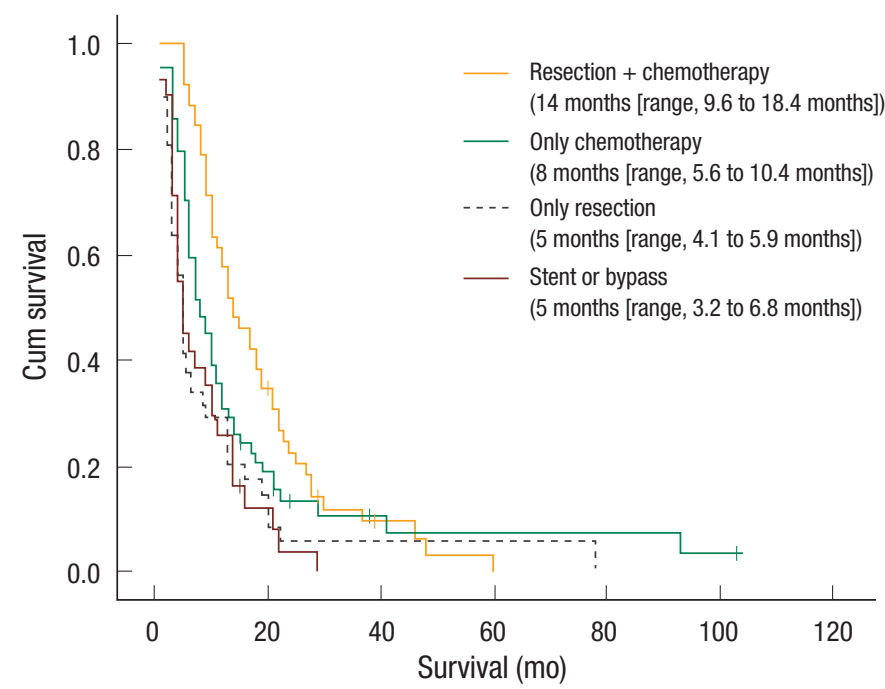

Fig. 2. Kaplan-Meier overall survival rate curve for patients with incurable stage IV colorectal cancer according to their initial management with resection and non-resection therapy. The survival rates for adjuvant chemotherapy, only resection therapy, only chemotherapy, and stent or bypass surgery were 14 months (range, 9.6 to 18.4 months), 5 months (range, 4.1 to 5.9 months), 8 months (range, 5.6 to 10.4 months), and 5 months (range, 3.2 to 6.8 months), respectively.

\section{DISCUSSION}

Colorectal cancer is one of the most common cancers in the US and Europe. In Korea, according to the 2008 statistics, colorectal cancer shows the third highest incidence following stomach cancer and thyroid cancer, and the rate is sharply increasing. About $20 \%$ of colorectal cancer cases are considered progressive, meaning radical treatment in not possible, and debates on appropriate treatment modalities are still going on. The palliative resection is one of the most frequently used methods, but not all advanced colorectal cancer patients are candidates for this treatment. Moreover, the post-operative death rate and the complication rate are known to be higher compared with those for chemotherapy, stent insertion or bypass; consequently, the palliative resection has been restrictively applied to relatively healthy patients with good condition overall and with low operative risk. This means that adopting a palliative resection as a standard treatment modality for advanced colorectal cancer patients is debatable [14]. A stent insertion or a bypass is used for the patients who cannot undergo a resection, but the use of those methods as a standard treatment modality is still questionable.

Different from the study results showing high survival rates after palliative resection treatments $[3,5,6,15]$, patients who underwent only resection of the primary lesion showed a 5-month median survival rate, which was shorter than the 8 months for the chemotherapy-alone treatment patients. This result implies that the conventional palliative-resection-only modality cannot promise a good result. According to other studies, compared with chemotherapy, survival periods may be further extended when the palliative resection is restrictively used for patients having remote metastasis without peritoneal metastasis $[3,9,10]$.

According to some studies, chemotherapy results in higher survival rates than palliative-resection-only does. Costi et al. [16] reported cases of higher survival rates with chemotherapy-alone treatment for patients having multiple metastases or peritoneal metastasis than with palliative-resection-only treatment [16]. Chemotherapy, such as the use of 5-fluorouracil, which was developed in the late 1980s, and combination therapy of various agents, which was developed in the late 1990s, can enhance response rates of treatments and extend survival periods. Use of irinotecan in the late 1990s extended survival rates further, and introduction of oxaliplatin in the 2000s contributed to much better treatment results $[12,17]$. In addition, with the combination therapy of bevacizumab and cetuximab, which were developed in the mid-2000s as targeted chemotherapy agents with oxaliplatin, 5-fluorouracil and leucovorin or irinotecan, 5-fluorouracil and leucovorin, tumor response rates and survival periods were further improved $[13,18]$. Furthermore, studies on stent insertion followed by chemotherapy and on a palliative resection followed by chemotherapy are in progress, and the importance of enhancing survival rate has been emphasized $[19,20]$.

At the point of diagnosing advanced colorectal cancer, 10 to $20 \%$ of the total cases are accompanied by partial obstruction and 8 to $29 \%$ by complete obstruction [21]. When emergency surgery is conducted for these patients, a 15 to $20 \%$ death rate and about a $50 \%$ complication rate are reported [22]. Since stent insertion was introduced in 1991 for treating colorectal cancer, it has been reported to be an effective non-surgical treatment that can relieve the symptoms of acute obstruction caused by the tumor [23-25]. In spite of the very common complications of stent insertion, such as migration of the stent, colon perforation and obstruction, the 6-month clinical success rate has been reported at $81 \%$ or more [24], and the median survival rate calculated through the present study was 5 months. Based on these results, stent insertion may be considered to be an effective treatment modality for advanced colorectal cancer. In addition, the stent-related death rate has been reported at about 0 to $0.6 \%[26,27]$. Considering the high post-operative complication rate and death rate of colorectal cancer patients with obstructions, stent insertion is considered to be an effective treatment modality for advanced colorectal cancer with acute obstructions not allowing a resection. However, stent-related complications reach about $30 \%[7,28]$, and patients who undergo stent insertion are usually in unfavorable conditions compared with surgical resection or chemotherapy patients. Moreover, it should be taken into consideration that stent insertion is not a treatment that can enhance the survival rate.

Another treatment for advanced colorectal cancer, such as a bypass including a colostomy, may also be an effective treatment modality for releasing an obstruction in colorectal cancer. Nevertheless, considering the risks involved in general anesthesia, as well as 
the complications and deaths related to surgery, this modality can be used only for releasing the obstruction, not for enhancing the survival rate. Like stent insertion, this is a limitation of the bypass [29]. In general, patients who receive non-resection treatments tend to have unfavorable conditions overall and to have many underlying diseases compared with patients who receive resection treatments [15]. According to many studies, such factors as multiple metastases, a tumor with poor differentiation, existence of ascites and age of 75 or older are related to low survival rates $[3,10$, 20]. Additionally, Kim et al. [29] reported that stage, pre-operative CEA values, invasions into blood vessels and nerves, and lymphatic metastasis affected the 5 -year survival rate of perforated colorectal cancer patients. According to the present study, however, age, location of the primary lesion, sex, pre-operative CEA values, multiple metastases and level of differentiation of the tumor do not affect survival rates.

Currently, no established guideline for the treatment of advanced colorectal cancer exists. As reported through many studies, it is evident that no single treatment modality can achieve an improvement in survival rate. Kleespies et al. [10] reported statistical numbers in an acceptable range of complication development after surgical resection of primary lesions. According to the authors' study, a $16.2 \%(17 / 105)$ post-operative major complication rate and a $2.86 \%(3 / 105)$ post-operative death rate, which are similar to those reported by Kleespies et al. [10], are in an acceptable range of complication development after surgical resection of primary lesions. Therefore, when patients are carefully selected, resection of the primary lesion may enhance the survival of the patients. By virtue of development of continuous and effective chemotherapy agents, significant improvements in survival rates may be attained. In addition, through the present study, a combination of palliative resection and post-operative chemotherapy was confirmed to further enhance survival rates, and this result coincides with that of Costi et al. [16].

Even though a palliative resection of the primary lesion of advanced colorectal cancer can relieve pain, bleeding and ileus and can enhance survival rates compared with chemotherapy-alone treatment, stent insertion or a bypass, a palliative-resection-only treatment is not considered to be effective due to the high complication rates caused by unfavorable conditions such as old age, chronic diseases, recurring ileus, high surgery-related death rate, and anticipated limited survival period. Accordingly, selection of patients should be very careful before conducting a palliative resection and post-operative chemotherapy. For acute obstruction patients who cannot undergo a resection, adjuvant therapy, such as stent insertion and bypass, may be conducted to relieve symptoms and to provide a bridge for a future palliative resection to enhance survival.

Because this study was a retrospective one, some attention is required for interpretation of the results. Patients, guardians and doctors were involved in selecting the treatment method, in which may increase the risk of error. Different chemotherapy agents were administered to patients, which also increase the in risk of errors. That the best treatment modality can only be decided based on a random prospective study is common knowledge.

In case of advanced colorectal cancer, good treatment results can hardly be obtained through a palliative-resection-only treatment compared with a non-resection treatment. Accordingly, upon consideration of the general condition of advanced colorectal cancer patients having accompanying symptoms, a combination of a palliative resection of the primary lesion and post-operative chemotherapy may enhance survival rates.

\section{CONFLICT OF INTEREST}

No potential conflict of interest relevant to this article was reported.

\section{REFERENCES}

1. Ministry for Health, Welfare and Family Affairs. Annual report of cancer incidence (2008) and survival (1993-2008) in Korea. Seoul: Ministry for Health, Welfare and Family Affairs; 2010.

2. Schmiegel W, Pox C, Adler G, Fleig W, Fölsch UR, Frühmorgen P, et al. S3-Guidelines Conference "Colorectal Carcinoma" 2004. Z Gastroenterol 2004;42:1129-77.

3. Ruo L, Gougoutas C, Paty PB, Guillem JG, Cohen AM, Wong WD. Elective bowel resection for incurable stage IV colorectal cancer: prognostic variables for asymptomatic patients. J Am Coll Surg 2003;196:722-8.

4. Mella J, Biffin A, Radcliffe AG, Stamatakis JD, Steele RJ. Population-based audit of colorectal cancer management in two UK health regions. Colorectal Cancer Working Group, Royal College of Surgeons of England Clinical Epidemiology and Audit Unit. Br J Surg 1997;84:1731-6.

5. Mäkelä J, Haukipuro K, Laitinen S, Kairaluoma MI. Palliative operations for colorectal cancer. Dis Colon Rectum 1990;33:846-50.

6. Liu SK, Church JM, Lavery IC, Fazio VW. Operation in patients with incurable colon cancer--is it worthwhile? Dis Colon Rectum 1997;40:11-4.

7. Beham A, Rentsch M, Püllmann K, Mantouvalou L, Spatz H, Schlitt HJ, et al. Survival benefit in patients after palliative resection vs non-resection colon cancer surgery. World J Gastroenterol 2006;12:6634-8.

8. Guba M, Bosserhoff AK, Steinbauer M, Abels C, Anthuber M, Buettner R, et al. Overexpression of melanoma inhibitory activity (MIA) enhances extravasation and metastasis of A-mel 3 melanoma cells in vivo. Br J Cancer 2000;83:1216-22.

9. Costi R, Mazzeo A, Di Mauro D, Veronesi L, Sansebastiano G, Violi V, et al. Palliative resection of colorectal cancer: does it prolong survival? Ann Surg Oncol 2007;14:2567-76.

10. Kleespies A, Füessl KE, Seeliger H, Eichhorn ME, Müller MH, Rentsch M, et al. Determinants of morbidity and survival after elective non-curative resection of stage IV colon and rectal cancer. Int J Colorectal Dis 2009;24:1097-109. 
11. de Gramont A, Figer A, Seymour M, Homerin M, Hmissi A, Cassidy J, et al. Leucovorin and fluorouracil with or without oxaliplatin as first-line treatment in advanced colorectal cancer. J Clin Oncol 2000;18:2938-47.

12. Cunningham D, Pyrhönen S, James RD, Punt CJ, Hickish TF, Heikkila R, et al. Randomised trial of irinotecan plus supportive care versus supportive care alone after fluorouracil failure for patients with metastatic colorectal cancer. Lancet 1998;352:1413-8.

13. Hurwitz H, Fehrenbacher L, Novotny W, Cartwright T, Hainsworth J, Heim W, et al. Bevacizumab plus irinotecan, fluorouracil, and leucovorin for metastatic colorectal cancer. N Engl J Med 2004;350: 2335-42.

14. Kang DB, Shin CY, Lee JK, Park WC. Multivariate analysis of the risk factors associated with complications and mortality after and emergency operation for obstructive, perforated colorectal cancer. J Korean Soc Coloproctol 2009;25:165-71.

15. Rosen SA, Buell JF, Yoshida A, Kazsuba S, Hurst R, Michelassi F, et al. Initial presentation with stage IV colorectal cancer: how aggressive should we be? Arch Surg 2000;135:530-4.

16. Costi R, Di Mauro D, Giordano P, Leonardi F, Veronesi L, Sarli L, et al. Impact of palliative chemotherapy and surgery on management of stage IV incurable colorectal cancer. Ann Surg Oncol 2010;17:432-40.

17. Scheithauer W, Rosen H, Kornek GV, Sebesta C, Depisch D. Randomised comparison of combination chemotherapy plus supportive care with supportive care alone in patients with metastatic colorectal cancer. BMJ 1993;306:752-5.

18. Petrelli N, Herrera L, Rustum Y, Burke P, Creaven P, Stulc J, et al. A prospective randomized trial of 5-fluorouracil versus 5-fluorouracil and high-dose leucovorin versus 5-fluorouracil and methotrexate in previously untreated patients with advanced colorectal carcinoma. J Clin Oncol 1987;5:1559-65.

19. Karoui M, Soprani A, Charachon A, Delbaldo C, Vigano L, Luciani A, et al. Primary chemotherapy with or without colonic stent for management of irresectable stage IV colorectal cancer. Eur J Surg Oncol 2010;36:58-64.
20. Stelzner S, Hellmich G, Koch R, Ludwig K. Factors predicting survival in stage IV colorectal carcinoma patients after palliative treatment: a multivariate analysis. J Surg Oncol 2005;89:211-7.

21. Kim JH, Shon DH, Cahng BI, Chung MK, Shim MC. Complete single stage management of left colon cancer obstruction with a new devices. J Korean Soc Coloproctol 2002;18:30-6.

22. Kim JY, Kim JS, Hur H, Min BS, Kim NK, Sohn SK, et al. Complication and relevant factors after an ileostomy for fecal diversion in a patient with rectal cancer. J Korean Soc Coloproctol 2009;25:81-7.

23. Shin SJ, Kim TI, Kim BC, Lee YC, Song SY, Kim WH. Clinical application of self-expandable metallic stent for treatment of colorectal obstruction caused by extrinsic invasive tumors. Dis Colon Rectum 2008;51:578-83.

24. Bittinger M, Messmann H. Self-expanding metal stents as nonsurgical palliative therapy for malignant colonic obstruction: time to change the standard of care? Gastrointest Endosc 2007;66:928-30.

25. Lee KM, Shin SJ, Hwang JC, Cheong JY, Yoo BM, Lee KJ, et al. Comparison of uncovered stent with covered stent for treatment of malignant colorectal obstruction. Gastrointest Endosc 2007;66: 931-6.

26. Sebastian S, Johnston S, Geoghegan T, Torreggiani W, Buckley M. Pooled analysis of the efficacy and safety of self-expanding metal stenting in malignant colorectal obstruction. Am J Gastroenterol 2004;99:2051-7.

27. Meisner S, Hensler M, Knop FK, West F, Wille-Jørgensen P. Self-expanding metal stents for colonic obstruction: experiences from 104 procedures in a single center. Dis Colon Rectum 2004;47:444-50.

28. Kim HH, Kim HK, Cho SH, Huh JW, Rhyu SY, Kim HR, et al. Usefulness of self-expandable metallic stents for malignant colon obstruction. J Korean Soc Coloproctol 2009;25:113-6.

29. Kim MS, Lim SW, Park SJ, Gwak G, Yang KH, Bae BN, et al. Survival rate and prognostic factors in perforated colorectal cancer patients: a case-control study. J Korean Soc Coloproctol 2010;26: 69-75. 